\title{
粒子分散複合材料のき裂先端近傍の弾性·弾塑性特異場に及ぼす 粒子寸法とはく離損侮の影響
}

\author{
東郷敬一郎 ${ }^{* 1}$, 藤井朋之 ${ }^{* 2}$, 加藤大輔 ${ }^{* 3}$, 島村佳伸 ${ }^{* 2}$
Influence of particle size and debonding damage on elastic and elastic-plastic singular fields around a crack-tip in particulate-reinforced composites

\author{
Keiichiro TOHGO ${ }^{* 3}$, Tomoyuki FUJII, Daisuke KATO \\ and Yoshinobu SHIMAMURA \\ *33izuoka Univ. Dept. of Mechanical Engineering \\ Johoku 3-5-1, Naka-ku, Hamamatsu, Shizuoka, 432-8561 Japan
}

\begin{abstract}
This paper deals with finite element analysis of a crack tip field in particulate-reinforced composites with debonding damage and containing various sized particles. The finite element method was developed based on a micromechanics model of particulate-reinforced composites which can describe the debonding damage of particles from matrix and particle size effect on deformation and damage. The micromechanics model based on the Eshelby's equivalent inclusion method and Mori-Tanaka's mean field concept has been extended to consider the particle size effect. The effect of the debonding damage evolution on a crack tip field is evaluated. The stress distribution ahead of a crack tip field shifts upward with decreasing particle size. The debonding occurs from a crack tip and progresses ahead of a crack tip. The stress reduction around a crack tip is attributed to loss of load carrying capability of particles by debonding between particles and matrix.
\end{abstract}

Key Words : Composite Material, Crack, Debonding Damage, Fracture Mechanics, Finite Element

Method

\section{1. 緒 言}

マトリックス中に粒子を分散させることで機械的特性 を改善した粒子分散複合材料の開発が行われている. 粒 子分散複合材料では，マトリックスと粒子のはく離，粒 子の割炕損傷の進行が機械的特性に大きな影響を及ぼす ことが報告されている. 著者らは, Eshelby の等価介在物 法と Mori-Tanaka の平均場理論に基づく複合材料の損傷 理論に，粒子寸法効果および粒子のはく離損傷を考慮で きるように拡張した微視力学モデルを開発した(1).

本研究では，拡張した微視力学モデルを有限要素法に 導入した. 本有限要素法は, 種々の寸法の粒子が分布し た複合材料は，各々の粒子寸法の複合材料の体積平均に より表現できるという仮定を導入した微視力学モデルに 基ついて開発された，開発した有限要素法を三点曲げ負 荷を受けるき裂牨に適用し，き裂先端場に及ぼす粒子寸 法効果, はく離損傷の影響を評価した.

\footnotetext{
${ }^{* 1}$ 正員, フェロー, 静岡大学 (广 $432-8561$ 浜松市中区城北 3-5-1)

"2 正員, 静岡大学工学部

*3静岡大学大学院

E-mail: tmktoug@ipc.shizuoka.ac.jp
}

\section{2. 有限要率法と解析方法}

$2 \cdot 1$ 增分形損傮理倫 著者らは Eshelby の等価 介在物法と Mori-Tanaka の平均場理論に基づき，は く離損傷が進行する複合材料の損傷理論を開発した (1). 増分変形に対する複合材料のひずみ増分, 応力 増分の関係は次式のように表される。

$$
\begin{aligned}
& d \varepsilon_{k k}=\frac{1}{3 \kappa_{\mathrm{t}}} d \sigma_{k k}+\frac{1}{3 \kappa_{\mathrm{d}}} \sigma_{k k}^{\mathrm{p}} d f \\
& d \varepsilon_{i j}{ }^{\prime}=\frac{1}{2 \mu_{\mathrm{t}}} d \sigma_{i j}{ }^{\prime}+\frac{1}{2 \mu_{\mathrm{d}}} \sigma^{\mathrm{p}}{ }_{i j}^{\prime} d f
\end{aligned}
$$

ここで，dfは増分変形の間にはく離する粒子体積率 の変化であり, $\kappa_{\mathrm{l}}, \kappa_{\mathrm{d}}, \mu_{\mathrm{t}}, \mu_{\mathrm{d}}$ はマトリックス, 粒子の弾 性係数により与えられる定数である.

\section{$2 \cdot 2$ 粒子寸法効果 複合材料の損傷理論への} 変形特性における粒子寸法効果の導入として, Nan-Clarke の方法を用いた(2). 複合材料のマトリッ クスの相当応力一相当ひずみ関係は, RumburgOsgood の式で表される.

$$
\varepsilon_{\mathrm{e}}^{0}=\frac{\sigma_{\mathrm{e}}^{0}}{E_{0}}+\lambda \frac{\sigma_{0}^{0}}{E_{0}}\left(\frac{\sigma_{\mathrm{c}}^{0}}{\sigma_{0}^{0}}\right)^{1 / n}
$$


ここで， $E_{0}, \sigma_{0}^{0}, n$ は，それぞれ，ヤング率，降伏 応力, 加工硬化指数で, גは材料定数である. 変形 特性における粒子寸法効果として, Nan らは, マト リックス材料の応力ーひずみ関係は複合材料中では 粒子の影響を受けるとし， $\sigma_{0}^{0}$ に対して以下の修正

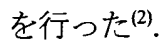

$$
\begin{aligned}
& \sigma_{0}^{0}=\left(\sigma_{0}^{0}\right)_{\text {Bulk }}+\Delta \sigma_{0}^{0} \\
& \left(\Delta \sigma_{0}^{0}\right)^{2}=\left(\Delta \sigma_{O R}^{0}+\Delta \sigma_{K N N}^{0}\right)^{2}+\left(\Delta \sigma_{I S O}^{0}\right)^{2}+\left(\Delta \sigma_{C T E}^{0}\right)^{2} \\
& =\left(\alpha \mu_{0} b \sqrt{\frac{4 f_{\mathrm{p}}}{\pi d^{2}}}+\beta \mu_{0} \sqrt{\frac{f_{\mathrm{p}} \varepsilon_{\mathrm{e}}^{0 \mathrm{p}} b}{d}}\right)^{2}+ \\
& +\left(\gamma \mu_{0} f_{\mathrm{p}} \sqrt{\frac{\varepsilon_{\mathrm{c}}^{0} b}{d}}\right)^{2}+\left(\eta \mu_{0} b \sqrt{\frac{6 \Delta T \Delta \theta f_{\mathrm{p}}}{b d\left(1-f_{\mathrm{p}}\right)}}\right)^{2}
\end{aligned}
$$

ここで, $\mu_{0}, b$ は，それぞれマトリックス材料のせ 儿断弾性係数, バーガースベクトルで, $d$ は粒子直 径, $\Delta T$ は熱処理時の温度と室温の温度差, $\Delta \theta$ はマ トリックス材料と粒子の熱膨張係数差である. $\alpha$, $\beta, \gamma, \eta$ は定数である.

はく離損傷における粒子寸法効果として，複合材 料中の粒子-マトリックス界面のはく離損傷は破壊 勒性により規定されると仮定すると，はく離損傷の 限界応力と粒子直径の関係は, エネルギーバランス により次式で表される.

$$
\sigma^{\mathrm{cr}}=\frac{K_{\mathrm{IC}}}{\sqrt{d}}
$$

ここで, $K_{\mathrm{IC}}$ は界面の限界応力拡大係数である.

$2 \cdot 3$ 粒子寸法分布の考虑 粒子寸法分布は対数 正規分布 $p(d)$ に従うものとした.

$$
p(d)=\frac{1}{\sqrt{2 \pi} \delta d} \exp \left[-\frac{(\ln d-\phi)^{2}}{2 \delta^{2}}\right]
$$

複合材料の巨視的特性に及ぼす各粒子の影響は体積 で表した割合 $p_{\mathrm{v}}(\mathrm{d})$ が有効であると推測できる.

$$
p_{\mathrm{v}}(d)=\frac{1}{\int d^{3} p(d) \mathrm{d} d} d^{3} p(d)
$$

複合材料の応力・ひずみ等の諸量を $A$ で表すと, 次 式より与えられる.

$$
A=\int p_{\mathrm{v}}(d) A(d) \mathrm{d} d
$$

ここで, $A(d)$ は粒子寸法 $d$ の複合材料の諸量の值で ある。

$2 \cdot 4$ 有限要素法 有限要素法では, 始めに各 ガウス積分点において, 各々の粒子寸法 $d_{i}(i=1 \sim \mathrm{n})$ の複合材料のひずみが等しいとして，応力ーひずみ マトリックス $\left[D_{i}\right]$ を算出し, 式(9)を用いて体積平均
により，粒子寸法が分布した複合材料の応力ーひず みマトリックス $\left[D_{\text {total }}\right]$ を求めた. そして全体剛性方程 式を構築し, 粒子寸法が分布した複合材料の応力・ ひずみを算出した．複合材料の応力・ひずみから， 個々の粒子寸法の複合材料のマトリックス・粒子の 諸量を算出した. そして，式(9)により粒子寸法分布 を考慮した複合材料におけるマトリックス・粒子の 諸量を求めた．また，応力ーひずみマトリックスを 算出する前に，式(4)により粒子寸法効果を考慮した 降伏応力を算出した. さらに，はく離損傷における 粒子寸法依存性を考慮するため, 応力ーひずみマト リックスを求める際に, 各ガウス積分点で式(6)のよ りはく離の有無を判断し，はく離条件を満たしてい る場合は，損傷量に応じて応力低下を算出した.

$2 \cdot 5$ 解析条件 有限要素解析では四角形八節 点要素を用い平面ひずみ条件で解析を行った．解析 対象は $\mathrm{SiC}$ 粒子強化アルミニウム合金複合材料 A356-T4/15vol\%SiC である.アルミニウム合金 $\mathrm{A} 356-\mathrm{T} 4$ の材料特性は $E_{0}=70 \mathrm{GPa}, \quad v_{0}=0.33$ ， $\left(\sigma_{0}^{0}\right)_{\text {Bulk }}=86 \mathrm{MPa}, n=0.212$, バーガースベクトル $b=0.283 \mathrm{~nm}, \lambda=3 / 7$ とした. $\mathrm{SiC}$ 粒子の材料特性は, $E_{\mathrm{p}}=427 \mathrm{GPa}, \quad v_{\mathrm{p}}=0.17$ である. 粒子体積率 $f_{\mathrm{p} 0}$ は $15 \%$ とし, $\Delta \theta=19.3 \times 10^{-6}\left(1 /{ }^{\circ} \mathrm{C}\right), \Delta T=520^{\circ} \mathrm{C}$ した. また, 式(5)における定数 $\alpha, \beta, \gamma, \eta$ は，それぞれ 1.8，0.4, 2.0，1.8 とした. 粒子寸法分布は平均粒径 $\bar{d}=1 \mu \mathrm{m}$ $(\delta=0.55, \phi=-0.151), \bar{d}=7.5 \mu \mathrm{m} \quad(\delta=0.55, \phi=1.864)$, $\bar{d}=16 \mu \mathrm{mm}(\delta=0.55, \phi=2.621)$ について解析を行った・ 図 1 に 3 点曲げ試験を再現した解析モデルおよび要 素分割を示す．対称性を考慮して $1 / 2$ モデルの解析 を行った. なお，き裂先端での応力特異性の問題を 避けるため, 鋭い切欠きをき裂とみなした. また, 3 点曲げ負荷における荷重一変位関倸より簡便法を用 いて J 積分を算出した.

\section{3. 解析結果と考察}

$3 \cdot 1$ 変形举勳に及ぼす粒子寸法勃果 図 2 に はく離損傷を考慮しない場合のき裂先端の応力分布 を示す. 図は縦軸に $\left(\sigma_{0}\right)_{\text {Bulk }}$ で無次元化した応力, 横

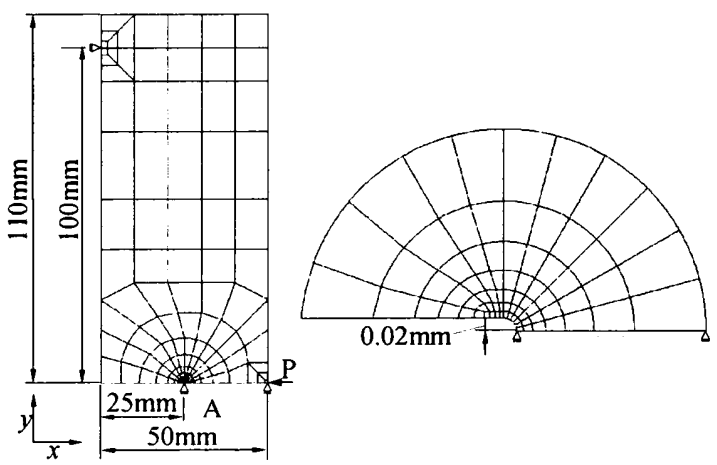

Fig. 1 Three-point-bending specimen and its finite element mesh. 
軸に $\mathrm{J}$ 積分の值 $J$ と $\left(\sigma_{0}{ }^{9}\right)_{\text {Bulk }}$ で無次元化したき裂先端 からの距離をとり, 両対数図上に示したものである. 忘力分布の傾きに着目すると, き裂先端近傍の塑性 変形域は傾き $-N /(N+1)(N$ は加工硬化指数 $)$ の直線 で表現される HRR 特異場が形成され, 弾性変形域 では傾きが $1 / 2$ の直線で表される K 特異場が形成さ れている。 また平均粒子寸法に着目すると，平均粒 子寸法が小さくなるほど高い応力分布となっている.

\section{$3 \cdot 2$ き裂先端近傍の応力分布に及ぼすはく離損伤の}

影整図 3 に, 平均粒径 $\bar{d}=16 \mu \mathrm{m}$ の複合材料にお ける $\mathrm{J}$ 積分 $J=1.0 \times 10^{3} \mathrm{~J} / \mathrm{m}^{2}$ でのき裂周りの相当応力 分布, 塑性変形領域, ボイド体積率分布を示したも のである。図 3(a)ははく離損傷を考慮しない場合 (NDD) の相当応力分布であり，図3(b)(c)はそれぞ れはく離損傷を考慮した場合 (DD) の相当応力分布 およびはく離損傷領域を示す.はく離損傷を考慮し た場合，切欠き先端近傍には，はく離損傷が生じて いる. はく離の有無による応力分布を比較すると, はく離損傷によって粒子が載荷能力を失うため，応 力分布がはく離損傷を考慮しない場合に比べて低下 していることがわかる.
図 4 に平均粒径 $16 \mu \mathrm{m}$ の場合におけるき裂先端の 応力およびボイド体積率の分布を示す．はく離損傷 を考慮しない場合を点線，はく離損傷を考慮した場 合を実線で示す．前述の通り，はく離損傷を考慮し た場合のき裂先端近傍の応力分布は，応力分布がは く離損傷を考慮しない場合に比べて低下している. また，粒子のはく離損傷領域と応力の低下領域は対 応しており,変形の進行に伴いはく離損傷が進行し, 応力低下の度合いも増大していることがわかる.ま た， $\mathrm{J}$ 積分の増大につれて，はく離損傷領域が拡大 するとともに，き裂先端近傍の応力分布の低下が顕 著になっていることがわかる.

\section{文献}

(1) Tohgo K, Itoh $Y$, Shimamura $Y$, A constitutive model of particulate-reinforced composites taking account of particle size effects and damage evolution, Composites Part A, 2010, Vol.41, pp.313-321.

(2) Nan CW, Clarke DR, The influence of particle size and particle fracture on the elastic/plastic deformation of metal matrix composites, Acta Materialia, 1996, Vol.44, pp.3801-3811.

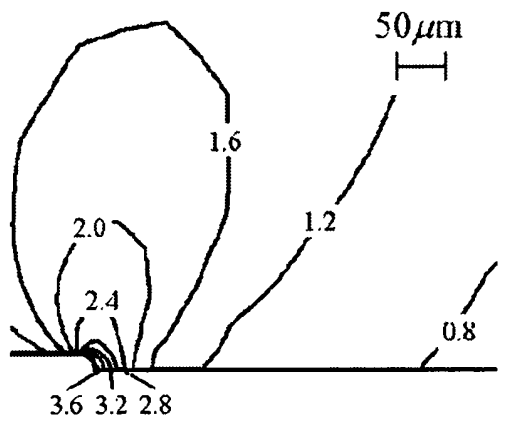

(a) Equivalent stress $\sigma_{\mathrm{e}} / \sigma_{0}$ (NDD)

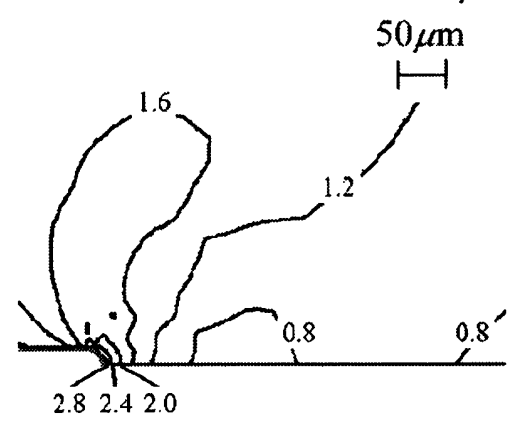

(b) Equivalent stress $\sigma_{\mathrm{e}} / \sigma_{0}$ (DD)

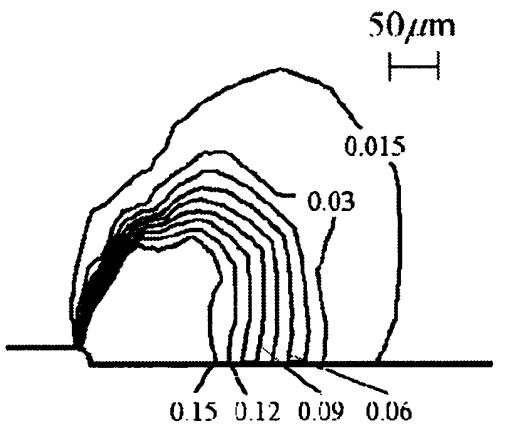

(c) Void volume fraction $f_{\mathrm{d}}(\mathrm{DD})$

Fig. 3 Distributions of equivalent stress $\sigma_{\mathrm{e}} / \sigma_{0}$, plastic deformation area and void volume fraction in the composites.

$\left(\bar{d}=16 \mu \mathrm{m}, J=1.0 \times 10^{3} \mathrm{~J} / \mathrm{m}^{2}\right)$

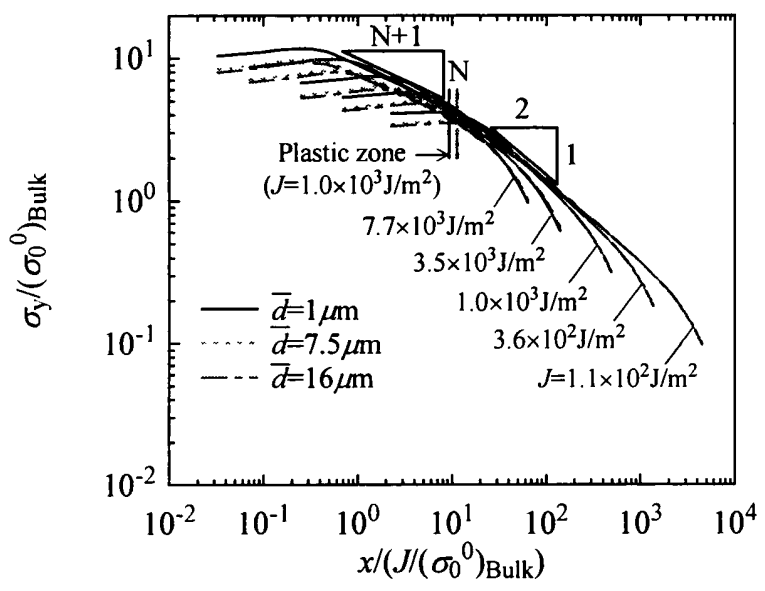

Fig. 2 Distributions of the stress ahead of a crack-tip without debonding damage.

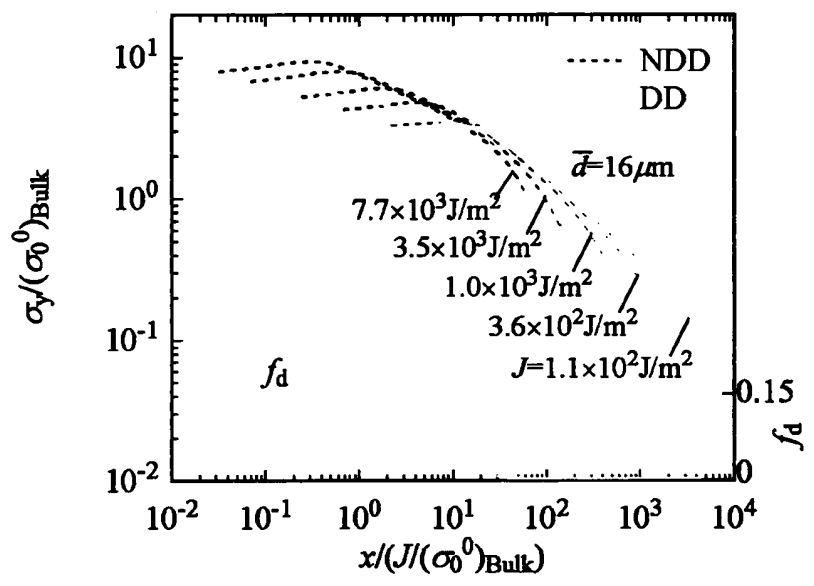

Fig. 4 Influence of debonding damage on distributions of the stress ahead of a crack-tip in the composite of $\bar{d}=16 \mu \mathrm{m}$. 